\title{
Trends and outcomes for cardiac surgery in the United Kingdom from 2002 to 2016
}

Stuart W. Grant, MBChB(Hons), MRCS, PhD, ${ }^{a}$ Simon Kendall, BSc, MBBS, MS, FRCS(CTh), ${ }^{\mathrm{b}}$ Andrew T. Goodwin, PhD, FRCS(CTh) ${ }^{\mathrm{b}}$ Graham Cooper, MD, FRCS(CTh), ${ }^{\mathrm{c}}$ Uday Trivedi, FRCS(CTh) ${ }^{\mathrm{d}}$ Richard Page, ChM, FRCS(CTh), ${ }^{e}$ and David P. Jenkins, BSc(Hons), MBBS(Lond), MS(Lond), FRCS(CTh) ${ }^{\mathrm{f}}$

\section{ABSTRACT}

Objectives: Cardiac surgery has evolved significantly since the turn of the century. The objective of this study was to investigate trends in cardiac surgery activity and outcomes in the United Kingdom utilizing a mandatory national cardiac surgical clinical database in the context of a comprehensive public health care system (ie, the UK National Health Service).

Methods: Data for all cardiac surgery procedures performed between 2002 and 2016 were extracted from the UK National Adult Cardiac Surgery Audit database. Data are validated and cleaned using reproducible algorithms. Trends in activity and outcomes were analyzed by fiscal year using linear regression.

Results: A total of 534,067 procedures were performed during the study period with the number of cases per year peaking in 2008/2009 at 41,426. Despite an increase in patient age and mean logistic European System for Cardiac Operative Risk Evaluation score, the in-hospital mortality rate for all cardiac surgery has fallen from $4.0 \%$ to $2.8 \%(P<.001)$. The number of isolated coronary artery bypass graft procedures has steadily declined but the total number of valve procedures has steadily increased (both $P$ values $<.001$ ). The number of thoracic aortic procedures performed each year has doubled $(P<.001)$, but the incidence of redo procedures has steadily declined. The proportion of emergency and salvage procedures has remained stable.

Conclusions: This study, which covers all cardiac surgery procedures performed in the United Kingdom for fiscal years between 2002 and 2016, demonstrates that despite an increase in patient risk profile, there has been a consistent reduction in in-hospital mortality. A number of other markers associated with quality have also improved. (JTCVS Open 2021;7:259-69)

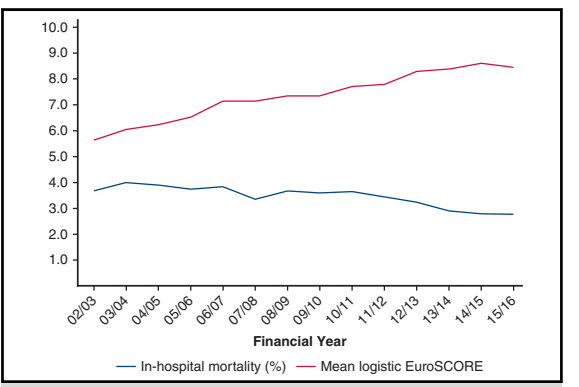

Decrease in UK cardiac surgery mortality despite increasing risk measured by EuroSCORE.

\section{CENTRAL MESSAGE}

Cardiac surgery practice has and continues to evolve in the United Kingdom. Despite increasing patient age and patient risk profiles, national outcomes have consistently improved.

\section{PERSPECTIVE}

Changing trends in cardiac surgery activity and outcomes have implications for patients, surgeons, and policy makers. This study summarizes changes that have occurred in cardiac surgery activity and outcomes from a complete national perspective between 2002 and 2016. Despite changes in patient risk profiles and operative workloads, outcomes have consistently improved.

See Commentaries on pages 270 and 272.
Cardiac surgery evolved into the speciality we recognize today following the successful introduction of cardiopulmonary bypass by John Gibbon in $1953 .{ }^{1}$ Although the

\footnotetext{
From the a Division of Cardiovascular Sciences, University of Manchester, Manchester, United Kingdom; ' James Cook University Hospital, Middlesbrough, United Kingdom; ${ }^{\text {c }}$ Sheffield Teaching Hospitals NHS Foundation Trust, Sheffield, United Kingdom; ${ }^{\mathrm{d}}$ Brighton and Sussex University Hospitals NHS Trust, Brighton, United Kingdom; ' ${ }^{\mathrm{L}}$ Liverpool Heart and Chest Hospital, Liverpool, United Kingdom; and ${ }^{\mathrm{f}}$ Royal Papworth Hospital NHS Foundation Trust, Cambridge, United Kingdom.

Supported by a grant from Heart Research UK, which funded the data extraction from the UK National Institute for Cardiovascular Outcomes Research.

Accepted for the 100th Annual Meeting of The American Association for Thoracic Surgery.
}

pace of evolution has slowed since the early days of the speciality, cardiac surgery continues to adapt and refine to deliver improved outcomes for patients with heart disease.

\footnotetext{
Received for publication Feb 2, 2021; accepted for publication Feb 2, 2021; available ahead of print March 13, 2021.

Address for reprints: David P. Jenkins, BSc(Hons), MBBS(Lond), MS(Lond), FRCS(CTh), Royal Papworth Hospital NHS Foundation Trust, Cambridge Biomedical Campus, Cambridge, CB2 OAY United Kingdom (E-mail: david. jenkins1@nhs.net).

2666-2736

Copyright (c) 2021 The Authors. Published by Elsevier Inc. on behalf of The American Association for Thoracic Surgery. This is an open access article under the CC BY-NC-ND license (http://creativecommons.org/licenses/by-nc-nd/4.0/). https://doi.org/10.1016/j.xjon.2021.02.001
} 


\section{Abbreviations and Acronyms \\ AVR = aortic valve replacement \\ CABG = coronary artery bypass graft \\ EuroSCORE $=$ European System for Cardiac Operative Risk Evaluation \\ LITA $\quad=$ left internal thoracic artery \\ NHS $\quad=$ National Health Service \\ PCI = percutaneous coronary intervention \\ SCTS $=$ The Society for Cardiothoracic Surgery in Great Britain and Ireland \\ TAVI $=$ transcatheter aortic valve implantation}

Minimally invasive approaches for procedures previously believed only possible via a median sternotomy have been developed and robotic cardiac surgery has become established. Advances in perioperative and postoperative care have enabled increasingly complex procedures to be performed in increasingly comorbid patients and alternative percutaneous treatment options have become established.

Within the past 20 years, a major development in the United Kingdom and Republic of Ireland (hereafter, United Kingdom refers to England, Northern Ireland, Republic of Ireland, Scotland, and Wales), has been the introduction of public reporting of surgical outcome data. The Society for Cardiothoracic Surgery (SCTS) represents cardiac surgery in Great Britain and Ireland and has a long history of collecting and benchmarking adult cardiac surgery data. In 1977 under the guidance of Sir Terence English, the SCTS established a cardiac surgery register and all hospitals were asked to submit data on a voluntary basis. ${ }^{2}$ Initially, mortality rates for specific operations were produced and outcomes were returned to each hospital to allow comparisons against overall pooled data. ${ }^{3}$ Improved data collection processes and infrastructure were developed over time, leading to a more comprehensive dataset that included preoperative patient characteristics, operative details and postoperative outcomes. ${ }^{4}$

These data were initially collated to allow trends in activity to be studied and to facilitate the understanding of the influence of differences in case mix on outcomes. However, following the public inquiry into the Bristol Royal Infirmary paediatric cardiac surgery deaths in 2001, these data became essential for facilitating the transparency that the inquiry recommended. ${ }^{5}$ Publication of cardiac surgical outcome data on a named hospital basis first took place in 2001. The SCTS published the names of all consultant surgeons together with a statement on whether they had achieved a defined mortality standard in 2004. A year later, a public portal was developed with the SCTS to place riskadjusted mortality data by individual named surgeon for index operations (eg, coronary artery bypass grafting
[CABG], and aortic valve replacement [AVR]) in the public domain. ${ }^{4}$ By 2008 , activity- and risk-adjusted mortality were published for individual surgeons for all cardiac surgery. Statistical analyses to describe average performance and outlier performance were also included and this has continued.

Although the United Kingdom has pioneered publication of risk-adjusted surgeon-specific cardiac surgery outcome data on a national basis, New York State has been reporting hospital-level risk-adjusted cardiac surgery outcome data since 1990 and surgeon-level outcome data since 1992. ${ }^{6,7}$ Across the United States, numerous initiatives with varied approaches on both a state and national level have resulted in the public reporting of cardiac surgery outcome data. ${ }^{8}$ Although other settings have longer-established programs of public reporting, and complete national datasets also exist, ${ }^{9}$ this SCTS database provides a unique opportunity to examine the changes in cardiac surgical activity and outcomes in the context of a comprehensive national public health care system (UK National Health Service [NHS]) in the era of public outcome reporting.

\section{MATERIALS AND METHODS}

Summary data were extracted from the UK National Adult Cardiac Surgery Audit database, which is run by the independent UK National Institute for Cardiovascular Outcomes Research. These extracted summary data included all adult cardiac surgery procedures (excluding transcatheter procedures) performed in UK NHS hospitals performed between fiscal years 2002 and 2016. Additional data from a small number of private hospitals in the United Kingdom and some hospitals in the Republic of Ireland that perform cardiac surgery were also included. Data are processed, validated, and cleaned using reproducible algorithms. The processes and principles of the SCTS Adult Cardiac Surgery Database have been described in detail previously. ${ }^{10,11}$ No patient identifiable information was available to the research team. Because only summary statistical data were available to the research team ethical approval and patient consent were not required. Trends in activity and outcomes were analyzed by fiscal year. Where applicable normally distributed summary data are presented as mean and standard deviation (SD). The logistic European System for Cardiac Operative Risk Evaluation (EuroSCORE), ${ }^{12}$ was used to allow comparisons in patient risk profiles over time. Linear regression was used to assess for significant trends over time. All statistical analyses were performed using SPSS version 25 (IBM-SPSS Inc, Armonk, NY).

\section{RESULTS}

\section{Overall Cardiac Surgery Activity}

A total of 534,067 procedures were performed during the study period. As shown in Figure 1, there has been significant variability in overall activity over this period. The number of cases per year peaked at 41,426 during 2008/ 2009 with a fall in activity toward the latter years of the study period. The total number of cases generally mirrors the trend in the number of contributing hospitals as shown in Figure 1. Over time there has been some variability in the number of contributing hospitals as new units have opened and others have amalgamated, but there has been a statistically significant linear increase in the number 


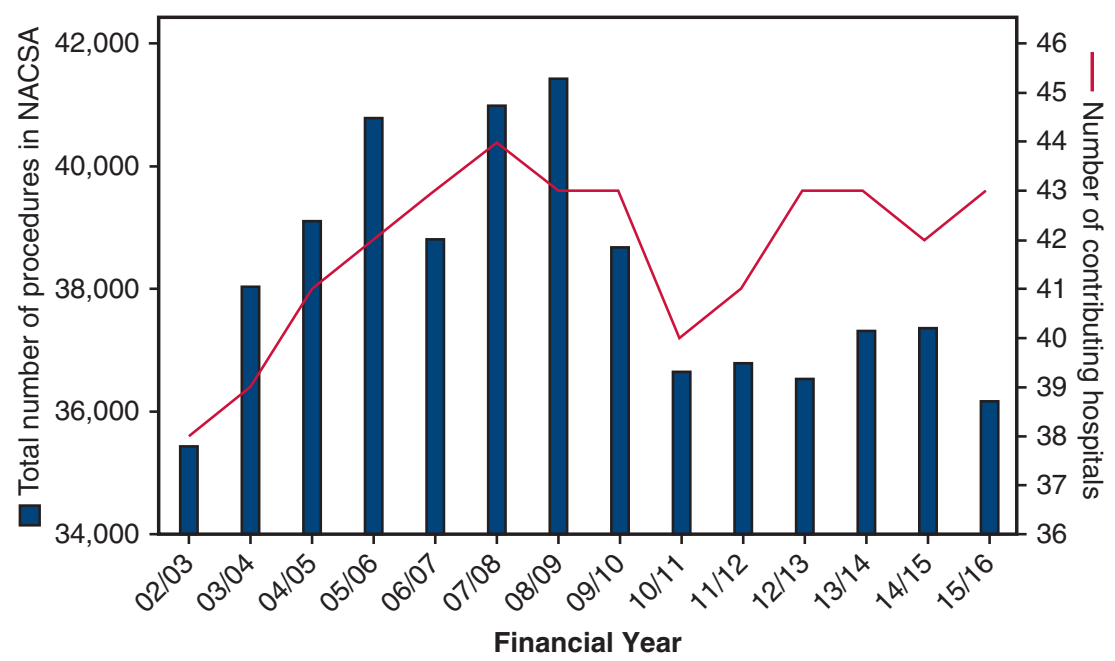

FIGURE 1. The total number of cardiac surgery procedures performed in the United Kingdom and Ireland between 2002 and 2016 (left y-axis) as recorded in the National Adult Cardiac Surgery Audit (NACSA) database along with the number of contributing hospitals (right y-axis) for each financial year.

of contributing surgeons over time $(P<.001)$. Detailed description of contributing hospitals and surgeons is provided in Table 1 . The mean \pm SD number of contributing hospitals and surgeons per year over the study period were $41.8 \pm 1.8$ and $260.1 \pm 18.1$, respectively.

\section{Patient Characteristics}

As shown in Table 2, the mean \pm SD age of patients increased from $64.2 \pm 10.9$ years in the first year of the study to plateau at $66.4 \pm 12.0$ years from 2010/2011 onward. This increase is statistically significant when modeled using linear regression $(P<.001)$. The majority of patients who undergo cardiac surgery in the United Kingdom and Ireland are men, but there has been a steady increase in the proportion of female patients over the study period $(P<.001)$. The incidence of moderate or poor left ventricular function has decreased over time $(P<.001)$, but there has been a significant $(P<.001)$ yearly increase over the study period in the number of patients undergoing surgery within 90 days of a myocardial infarction. There has not been a significant change over time in the incidence of extracardiac arteriopathy $(P=.239)$. There has been a significant linear increase in the incidence of pulmonary disease and the incidence of active endocarditis

TABLE 1. Number of contributing hospitals and surgeons to the National Adult Cardiac Surgery Audit Database by financial year over the study period

\begin{tabular}{|c|c|c|c|c|c|c|}
\hline Study year & $\begin{array}{c}\text { Contributing } \\
\text { hospitals }\end{array}$ & $\begin{array}{c}\text { Contributing } \\
\text { surgeons }\end{array}$ & Total No. of cases & Cases per surgeon & In-hospital mortality & $\begin{array}{l}\text { Mean logistic } \\
\text { EuroSCORE }\end{array}$ \\
\hline $02 / 03$ & 38 & 219 & 35,435 & 161.8 & 3.7 & $5.6 \pm 8.7$ \\
\hline $03 / 04$ & 39 & 239 & 38,036 & 159.1 & 4.0 & $6.1 \pm 9.0$ \\
\hline $04 / 05$ & 41 & 246 & 39,105 & 159.0 & 3.9 & $6.2 \pm 9.2$ \\
\hline $05 / 06$ & 42 & 248 & 40,784 & 164.5 & 3.8 & $6.5 \pm 9.8$ \\
\hline 06/07 & 43 & 247 & 38,808 & 157.1 & 3.8 & $7.1 \pm 10.1$ \\
\hline 07/08 & 44 & 263 & 40,983 & 155.8 & 3.4 & $7.1 \pm 10.1$ \\
\hline 08/09 & 43 & 261 & 41,426 & 158.7 & 3.7 & $7.3 \pm 10.2$ \\
\hline $09 / 10$ & 43 & 270 & 38,678 & 143.3 & 3.6 & $7.4 \pm 10.0$ \\
\hline $10 / 11$ & 40 & 268 & 36,648 & 136.7 & 3.7 & $7.7 \pm 10.5$ \\
\hline $11 / 12$ & 41 & 266 & 36,789 & 138.3 & 3.4 & $7.8 \pm 10.7$ \\
\hline $12 / 13$ & 43 & 274 & 36,533 & 133.3 & 3.2 & $8.3 \pm 11.5$ \\
\hline $13 / 14$ & 43 & 277 & 37,315 & 134.7 & 2.9 & $8.4 \pm 11.5$ \\
\hline $14 / 15$ & 42 & 285 & 37,361 & 131.1 & 2.8 & $8.6 \pm 11.6$ \\
\hline $15 / 16$ & 43 & 278 & 36,166 & 130.1 & 2.8 & $8.5 \pm 11.4$ \\
\hline
\end{tabular}

Values are presented as $\mathrm{n}$ or mean \pm standard deviation. EuroSCORE, European System for Cardiac Operative Risk Evaluation score. 
TABLE 2. Characteristics of patients undergoing cardiac surgery in the United Kingdom and Ireland between 2002 and 2016

\begin{tabular}{|c|c|c|c|c|c|c|c|c|}
\hline Study year & Mean age (y) & Female & $\begin{array}{l}\text { Moderate } \\
\text { LV function }\end{array}$ & $\begin{array}{l}\text { Poor LV } \\
\text { function }\end{array}$ & $\begin{array}{c}\text { Pulmonary } \\
\text { disease }\end{array}$ & $\begin{array}{c}\text { Extra-cardiac } \\
\text { arteriopathy }\end{array}$ & Recent MI & Active endocarditis \\
\hline $02 / 03$ & $64.2 \pm 10.9$ & 26.2 & 25.8 & 6.4 & 11.8 & 10.7 & 13.6 & 1.0 \\
\hline 03/04 & $64.7 \pm 11.2$ & 26.4 & 25.3 & 6.1 & 11.6 & 10.7 & 12.4 & 1.2 \\
\hline $04 / 05$ & $65.1 \pm 11.1$ & 26.7 & 25.6 & 6.3 & 12.7 & 12.0 & 13.0 & 1.2 \\
\hline $05 / 06$ & $65.3 \pm 11.1$ & 27.2 & 25.3 & 6.3 & 13.8 & 12.3 & 15.0 & 1.5 \\
\hline $06 / 07$ & $65.7 \pm 11.4$ & 27.1 & 25.4 & 7.0 & 12.6 & 12.0 & 15.6 & 1.7 \\
\hline 07/08 & $65.7 \pm 11.6$ & 27.2 & 25.2 & 6.4 & 12.8 & 12.4 & 16.0 & 1.7 \\
\hline 08/09 & $66.2 \pm 11.6$ & 27.7 & 24.9 & 6.2 & 13.4 & 12.6 & 16.3 & 1.8 \\
\hline $09 / 10$ & $66.2 \pm 11.9$ & 27.5 & 23.3 & 6.2 & 12.9 & 11.9 & 16.8 & 1.9 \\
\hline $10 / 11$ & $66.4 \pm 12.0$ & 27.9 & 21.5 & 6.0 & 13.6 & 11.9 & 19.2 & 1.9 \\
\hline $11 / 12$ & $66.4 \pm 12.0$ & 28.1 & 21.8 & 5.6 & 13.6 & 11.2 & 19.9 & 1.8 \\
\hline $12 / 13$ & $66.5 \pm 12.2$ & 27.7 & 21.9 & 5.4 & 13.8 & 11.3 & 19.0 & 2.1 \\
\hline $13 / 14$ & $66.3 \pm 12.1$ & 27.7 & 22.0 & 5.1 & 14.0 & 10.8 & 19.6 & 2.1 \\
\hline $14 / 15$ & $66.3 \pm 12.1$ & 27.5 & 20.9 & 4.5 & 14.3 & 10.8 & 17.8 & 2.1 \\
\hline $15 / 16$ & $66.4 \pm 12.0$ & 28.3 & 21.1 & 4.5 & 9.9 & 10.4 & 17.8 & 2.4 \\
\hline
\end{tabular}

Values are presented as \pm standard deviation or $\% . L V$, Left ventricular; $M I$, myocardial infarction.

(both $P$ values $<.001$ ) over the study period. The incidence of cardiac surgery for active endocarditis has more than doubled from the first to the last year of the study. Trends in patient characteristics over time are displayed in Figures 2 and 3.

\section{Procedure Groups}

As shown in Table 3, there has been a consistent and significant linear decline in the number of isolated CABG procedures performed over the study period $(P<.001)$. The number of CABG procedures has decreased by $33.9 \%$ from the first to last year of the study period. Combined CABG and valve surgery initially increased and peaked in 2008/2009 with more than 5000 procedures performed; however, more recently the number of combined CABG and valve procedures has declined. There has been a consistent increase in the number of patients undergoing any valve surgery and isolated valve surgery $(P<.001$ and $P=.007$, respectively, for linear increase). The overall number of valve procedures has increased by $70.7 \%$ from the first to last year of the study and the number of isolated valve procedures has increased by $42.5 \%$. This increase in activity has been significant across both AVR surgery $(P<.001)$ and mitral valve surgery $(P=.001)$. The number of patients undergoing thoracic aortic surgery has more than doubled during the study period $(P<.001$ for linear increase). Trends in procedural groups over time are displayed in Figures 4 and 5.

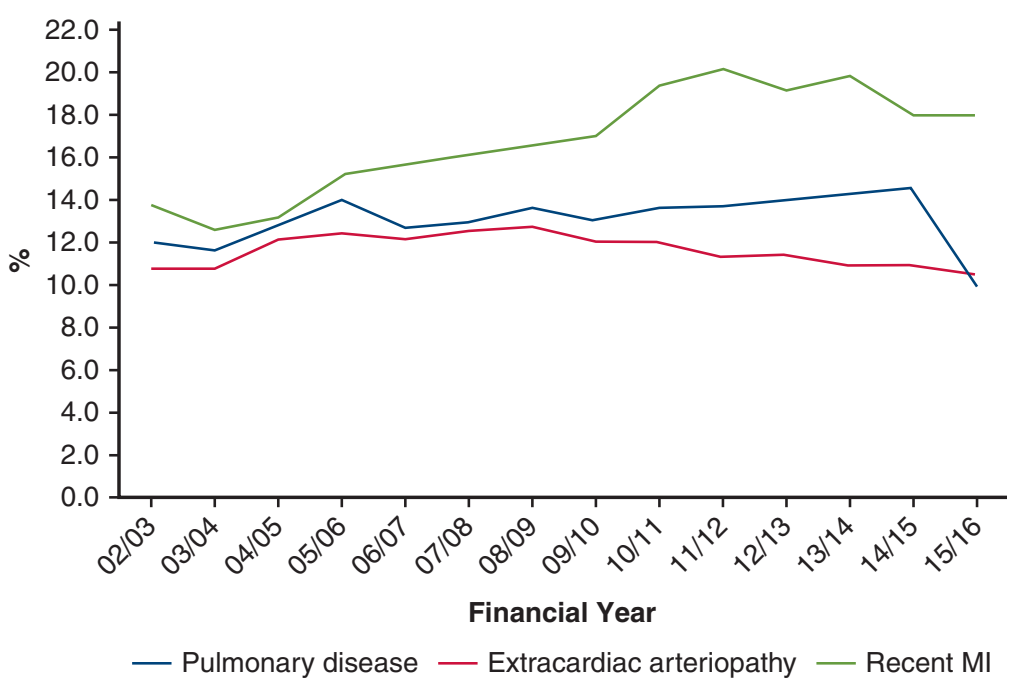

FIGURE 2. Yearly incidence of pulmonary disease, extracardiac arteriopathy, and recent myocardial infarction $(M I)$ in patients undergoing cardiac surgery in the United Kingdom and Ireland between 2002 and 2016. 


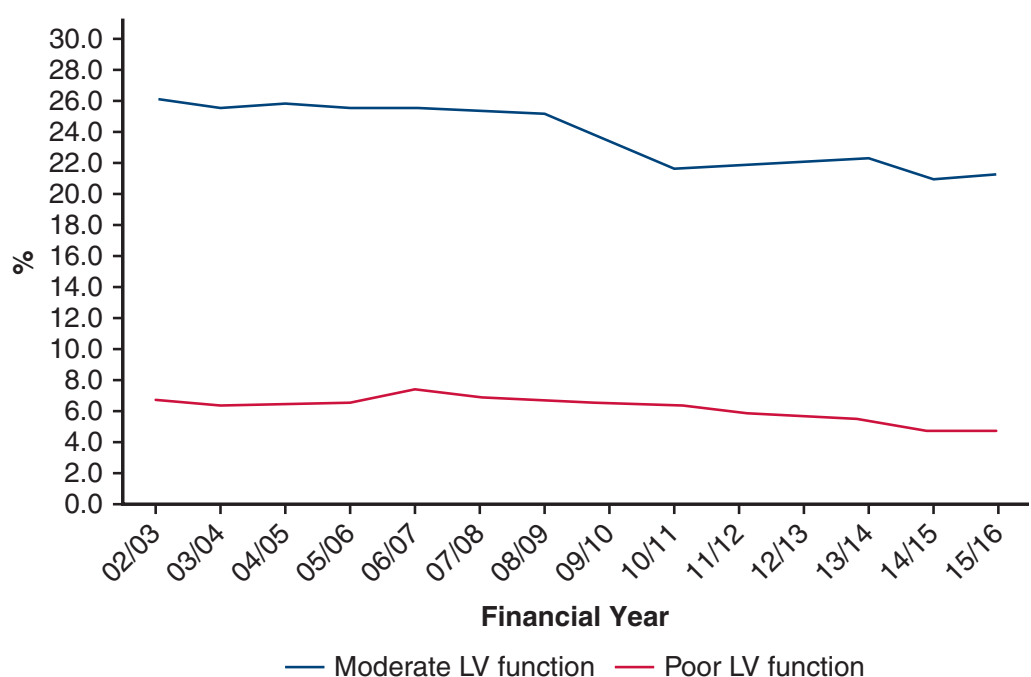

FIGURE 3. Yearly incidence of moderate or severe left ventricular $(L V)$ dysfunction in patients undergoing cardiac surgery in the United Kingdom and Ireland between 2002 and 2016.

As shown in Table 4, there has been a consistent and significant reduction in the proportion of cardiac surgery procedures performed on an elective basis over the course of the study period $(P<.001)$. This has been mirrored by a corresponding general increase in the incidence of urgent procedures $(P<.001)$. The incidence of emergency or salvage surgery has remained relatively constant at around $4.0 \%$. The incidence of emergency surgery is approximately $3.5 \%$ throughout the study period with salvage surgery representing consistently $<0.6 \%$ of all cardiac surgical activity. The incidence of redo cardiac surgery has generally declined over the study period and represents only $1 \%$ of all procedures in the most recent year.

\section{Outcomes and Quality}

Despite an increase in mean patient age and logistic EuroSCORE, as summarized in the Figure 6, outcomes and markers of quality have consistently improved. The mean \pm SD logistic EuroSCORE has consistently increased from $5.6 \pm 8.7$ during the first year of the study to $8.5 \pm 11.4$ in the final year $(P<.001$ for linear trend). In-hospital mortality for all cardiac surgery has significantly decreased $(P<.001$ for linear trend). The mortality rate in the most recent study year was $2.8 \%$. As shown in Figure 7 , there has been a consistent divergence between the mean logistic EuroSCORE and the observed in-hospital mortality rate. In the most recent year of the study, the mortality rate for

TABLE 3. Number of cardiac surgery procedures performed for specific procedural groups in the United Kingdom and Ireland between 2002 and 2016

\begin{tabular}{|c|c|c|c|c|c|c|c|}
\hline Study year & Isolated CABG & $\begin{array}{c}\text { Total valve } \\
\text { surgery }\end{array}$ & CABG and valve & $\begin{array}{c}\text { Isolated valve } \\
\text { surgery }\end{array}$ & $\begin{array}{l}\text { Aortic valve } \\
\text { replacement }\end{array}$ & $\begin{array}{c}\text { Mitral valve } \\
\text { surgery }\end{array}$ & $\begin{array}{c}\text { Thoracic aortic } \\
\text { surgery }\end{array}$ \\
\hline $02 / 03$ & 23,605 & 10,242 & 3274 & 6408 & 7009 & 3458 & 615 \\
\hline 03/04 & 24,335 & 11,768 & 3842 & 7147 & 8145 & 3929 & 643 \\
\hline $04 / 05$ & 24,565 & 12,583 & 4063 & 7420 & 8661 & 4210 & 631 \\
\hline $05 / 06$ & 24,316 & 14,359 & 4766 & 8107 & 10,132 & 4694 & 709 \\
\hline $06 / 07$ & 22,233 & 14,338 & 4707 & 7883 & 9969 & 4730 & 851 \\
\hline 07/08 & 23,407 & 15,223 & 4769 & 8497 & 10,629 & 4859 & 922 \\
\hline 08/09 & 22,159 & 16,673 & 5194 & 9261 & 11,800 & 5306 & 1123 \\
\hline $09 / 10$ & 20,156 & 16,000 & 4870 & 8986 & 11,343 & 4929 & 1138 \\
\hline $10 / 11$ & 18,616 & 15,550 & 4592 & 8510 & 11,061 & 4694 & 1191 \\
\hline $11 / 12$ & 16,895 & 16,099 & 4202 & 8162 & 11,484 & 4774 & 1027 \\
\hline $12 / 13$ & 16,210 & 16,543 & 4403 & 8153 & 11,857 & 4877 & 1185 \\
\hline $13 / 14$ & 15,712 & 16,822 & 4098 & 8027 & 11,973 & 4982 & 1121 \\
\hline $14 / 15$ & 15,596 & 17,494 & 4216 & 8622 & 12,483 & 5196 & 1350 \\
\hline $15 / 16$ & 15,078 & 17,486 & 4113 & 9129 & 12,322 & 5016 & 1254 \\
\hline
\end{tabular}

$C A B G$, Coronary artery bypass graft. 


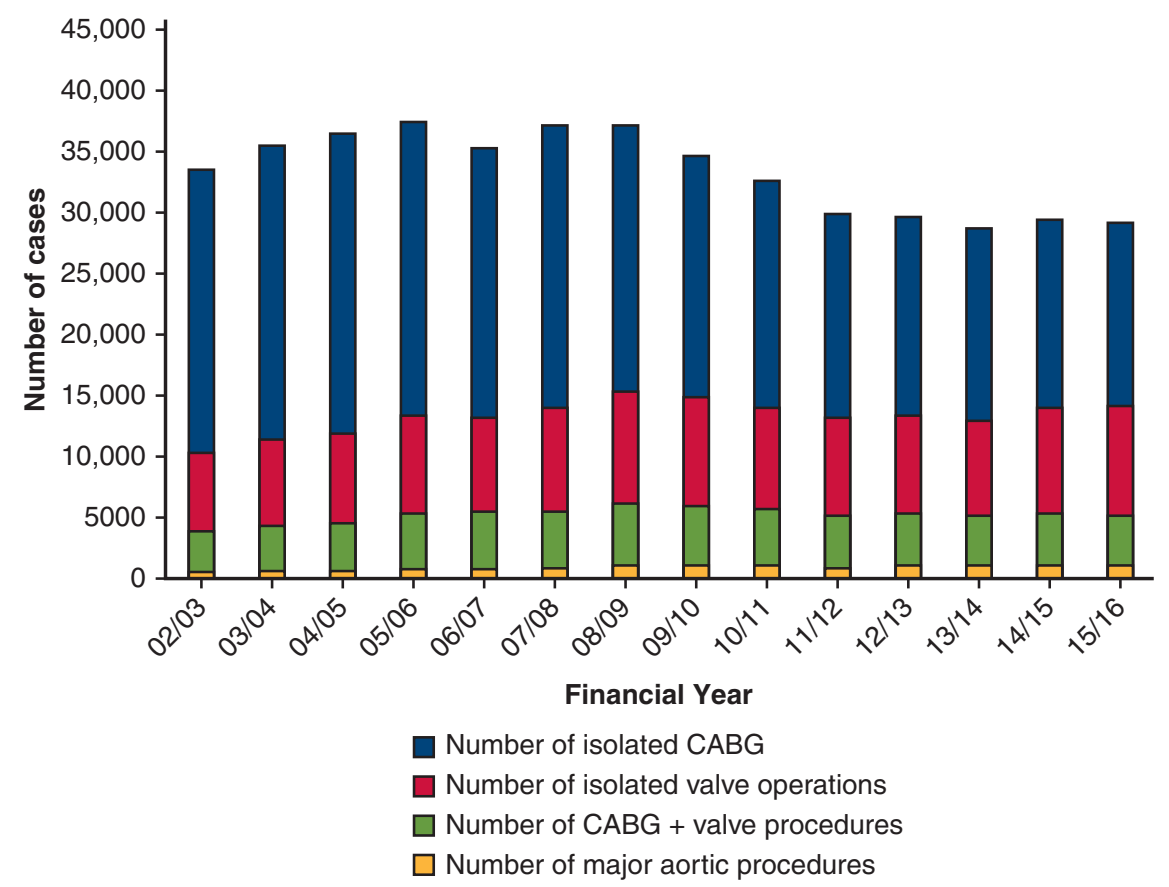

FIGURE 4. The number of cases performed by procedural group in the United Kingdom and Ireland between 2002 and 2016 as recorded in the National Adult Cardiac Surgery Audit (NACSA) database. $C A B G$, Coronary artery bypass grafting.

isolated CABG was $1.0 \%$ across all operative urgencies, with the mortality rate for elective isolated CABG $0.6 \%$. The most recent mortality rate for isolated AVR across all operative urgencies was $1.7 \%$. There has been a significant linear increase in the proportion of CABG cases that use a left internal thoracic artery (LITA) graft $(P=.001)$. The overall mitral valve repair rate (for all mitral valve pathologies) has significantly increased from $40.1 \%$ during the first year of the study to $63.0 \%$ in the final year of the study
$(P<.001$ for linear increase). LITA use (all CABG) and elective mitral valve repair rates are shown in Figure 8.

\section{DISCUSSION}

This study is the first to examine the changes in cardiac surgical activity and outcomes in the context of a comprehensive national health care system with compulsory data reporting and complete case attainment in the modern era of public outcome reporting. The objective of this study

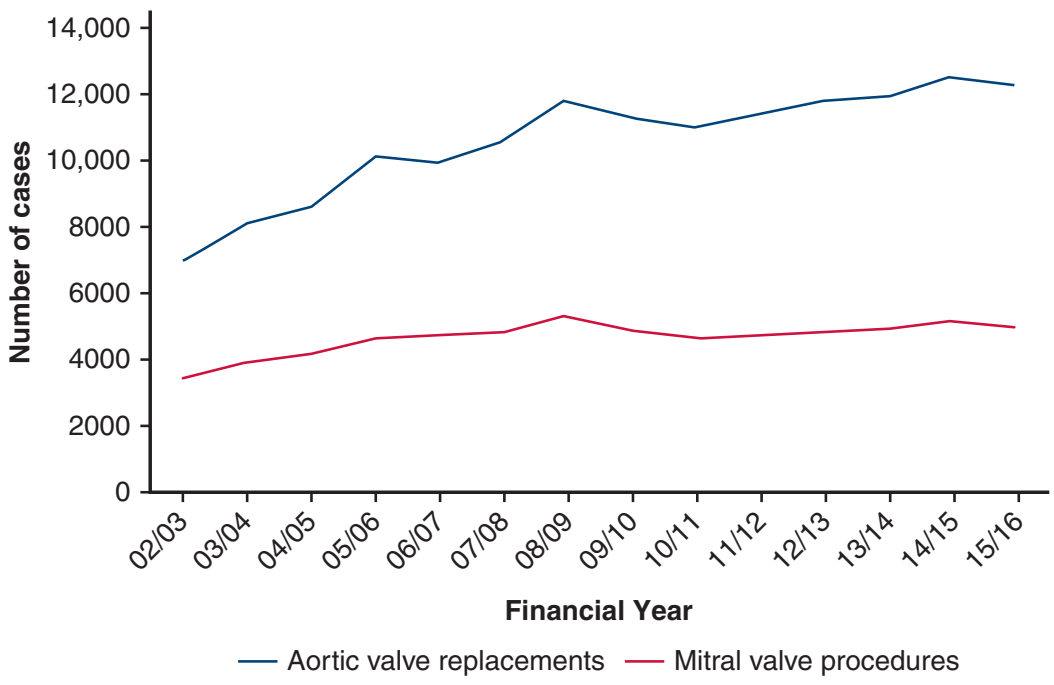

FIGURE 5. The number of aortic valve replacements and mitral valve procedures performed in the United Kingdom and Ireland between 2002 and 2016 as recorded in the National Adult Cardiac Surgery Audit Database. 
TABLE 4. Yearly proportion of all cardiac surgical activity performed on an elective, urgent, emergency/salvage or redo basis in the United Kingdom and Ireland between 2002 and 2016

\begin{tabular}{lcccc}
\hline Study year & Elective surgery & Urgent surgery & Emergency/salvage surgery & Redo surgery \\
\hline $02 / 03$ & 72.3 & 23.0 & 4.0 & 4.0 \\
$03 / 04$ & 71.0 & 24.3 & 4.0 & 1.9 \\
$04 / 05$ & 70.7 & 24.9 & 3.8 & 2.0 \\
$05 / 06$ & 69.2 & 26.8 & 4.1 & 1.7 \\
$06 / 07$ & 68.4 & 27.3 & 4.2 & 2.1 \\
$07 / 08$ & 68.8 & 26.9 & 3.6 & 1.9 \\
$08 / 09$ & 69.5 & 26.8 & 3.5 & 2.2 \\
$09 / 10$ & 69.1 & 27.2 & 3.9 & 2.0 \\
$10 / 11$ & 67.1 & 28.7 & 3.8 & 1.9 \\
$11 / 12$ & 66.5 & 29.7 & 4.0 & 1.8 \\
$12 / 13$ & 65.6 & 30.3 & 4.0 & 1.7 \\
$13 / 14$ & 64.9 & 31.1 & 3.9 & 1.6 \\
$14 / 15$ & 65.7 & 30.4 & 4.0 & 1.3 \\
$15 / 16$ & 64.9 & 31.1 & & 1.0 \\
\hline
\end{tabular}

Values are presented as $\%$.

was to provide an overview of national cardiac surgery trends over time rather than provide detailed insights into specific procedural groups. This information is potentially useful for the wider cardiac surgical community as changes such as those observed in our data may provide insights into emerging trends in other countries.

Despite an increase in the risk profile of patients undergoing surgery, reflected by a consistent upwards trend in the

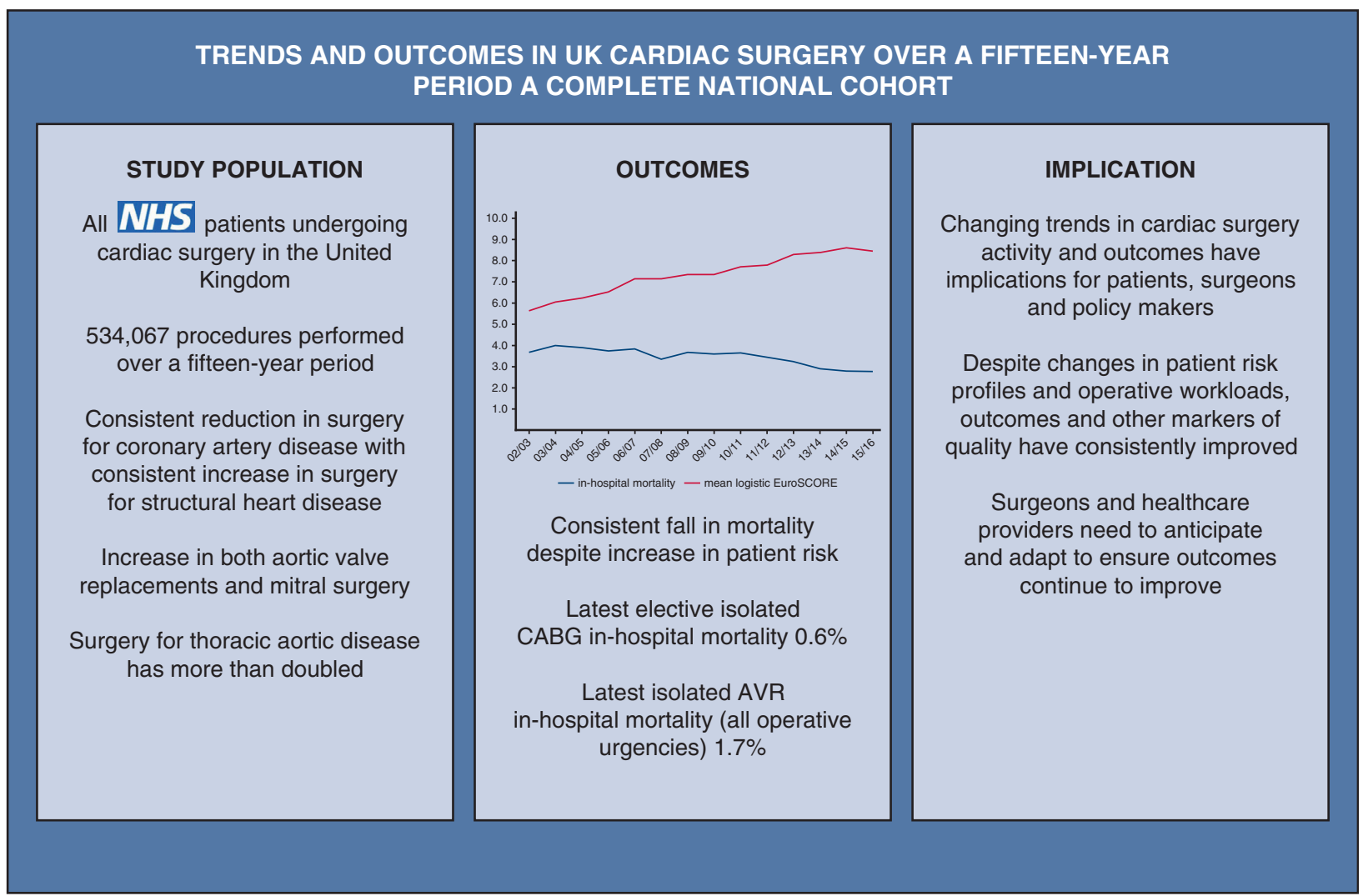

FIGURE 6. A summary of the key findings from an analysis of 14 years of United Kingdom and Ireland cardiac surgery activity between 2002 and 2016. $N H S$, National Health Service; $C A B G$, coronary artery bypass grafting; $A V R$, aortic valve replacement. 


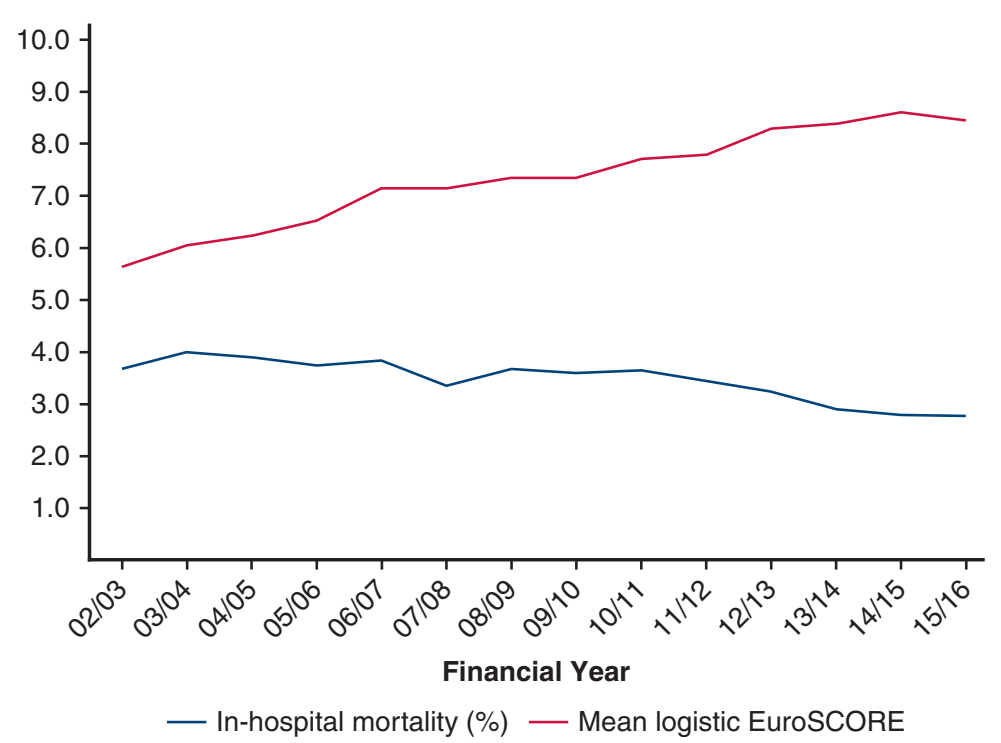

FIGURE 7. Yearly mean logistic European System for Cardiac Operative Risk Evaluation (EuroSCORE) score and observed in-hospital mortality rates for cardiac surgery procedures performed in the United Kingdom and Ireland between 2002 and 2016.

logistic EuroSCORE, in-hospital mortality has consistently reduced over time. The logistic EuroSCORE is known to be poorly calibrated for contemporary cardiac surgery, ${ }^{13}$ and significantly overestimated the risk of cardiac surgery in our cohort as early as 2002/2003. As such, the improvement in observed to expected outcomes should be interpreted in this context. However logistic EuroSCORE provides a consistent benchmark. EuroSCORE II was developed midway through the study period it would not have been possible to use EuroSCORE II to facilitate a risk profile analysis over the entire study period as some of the risk factors were not in the original dataset. ${ }^{14}$
The fall in in-hospital mortality rates across procedure groups despite an overall increase in risk profile can be seen as both a marker of improved safety and quality. In hospital mortality rate for isolated CABG and AVR across all operative urgencies (eg, elective, urgent, emergency, and salvage surgery) are now $1.0 \%$ and $1.7 \%$, respectively. The crude in-hospital mortality rate for all CABG of $1.0 \%$ is lower than that reported in other large national cardiac surgery registries., ${ }^{9,15}$ Other markers of quality have also improved over the study period. These include an increase in the proportion of patients undergoing mitral surgery who receive a repair and an increase to more than

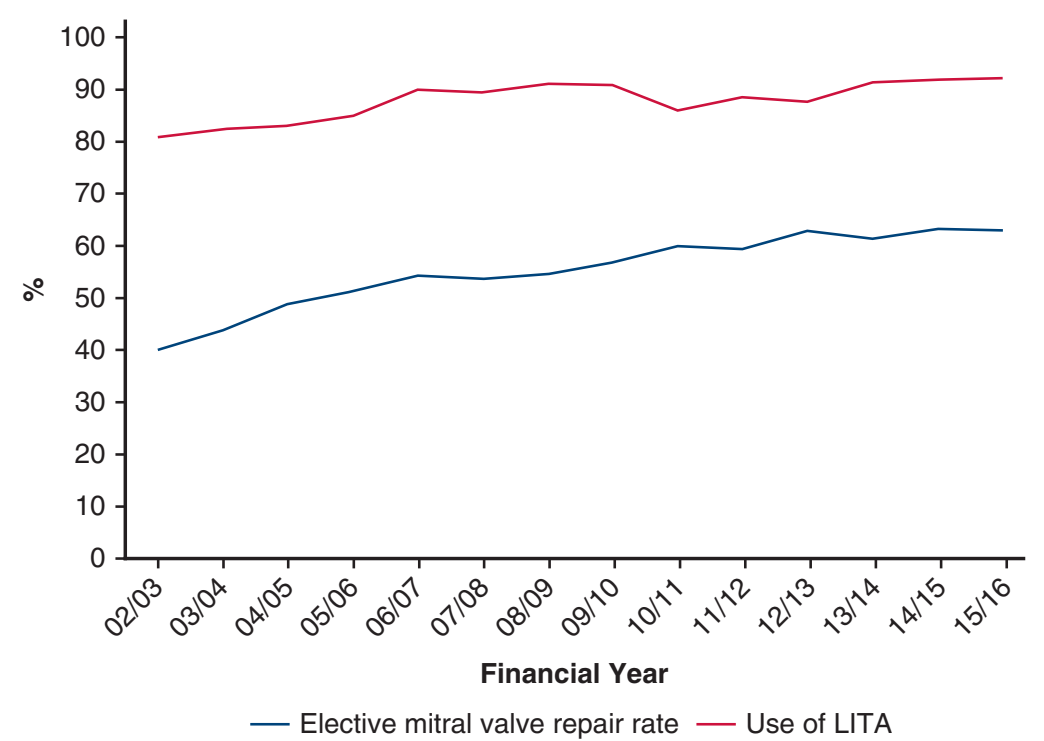

FIGURE 8. Yearly elective mitral valve repair rates and proportion of coronary artery bypass graft cases utilizing a left internal thoracic artery (LITA) graft for cardiac surgery in the United Kingdom and Ireland between 2002 and 2016. 
$92 \%$ of patients who undergo $\mathrm{CABG}$ who receive an LITA graft.

Over the course of this study, considerable changes in the activity of cardiac surgeons have been observed. A reduction in total activity over the time frame studied is apparent. From a peak in cases of more than 41,000 in 2008/2009 the number of cases has been relatively stable, but not exceeded 38,000 since. There has been fluctuation in the number of hospitals contributing data each year. This is a result of changes in reporting requirements for the small number of private hospitals included over time and some amalgamation of services into larger NHS organizations.

The number of contributing surgeons has consistently increased and as a result of the falling overall case numbers, the average number of cases per contributing surgeon each year has fallen by approximately 30 cases. This is likely to be as a result of both an increase in the complexity of cases over time and more general changes in working practices amongst surgeons. Over the era of this study there has been a change in the United Kingdom toward consultantdelivered surgical care, an expansion in consultant numbers and trainee working practices have been influenced by European working time directive limitations.

Perhaps the most significant overall clinical trend observed in this study is the shift from the surgical treatment of coronary artery disease to the treatment of structural heart disease. For the first 4 years of the study, between 23,000 and 25,000 isolated CABG procedures were performed each year. In the final year of the study only 15,078 isolated CABG procedures were performed. In contrast, there has been an increase of more than 7000 valve procedures performed from the first to the final year of the study. Similar trends have been observed in other national datasets, ${ }^{16}$ and a number of factors are likely to be responsible for this change.

The decline in CABG surgery is almost inevitably a result of percutaneous coronary intervention (PCI) becoming established for the treatment of less complex coronary artery disease. Technical developments allowing the treatment of highly complex coronary artery disease, previously considered only suitable for surgical intervention have also occurred. Although the growth of PCI activity has slowed in recent years, during the early years of this study it has been exponential. ${ }^{17}$ Given that the prevalence of coronary heart disease has remained stable over the study period, ${ }^{18}$ the increase in PCI is inevitably the primary driver in the decline in CABG surgery, but increased awareness and guidelines related to primary and secondary prevention medications may also have played a role.

The corresponding increase in surgery for structural heart disease is almost inevitably a consequence of an ageing population and the increased incidence of degenerative valvular pathology with advancing age. The development and introduction of transcatheter aortic valve implantation
(TAVI) into clinical practice over the study period will inevitably have an influence on cardiac surgical activity. In the United Kingdom, the first TAVI was performed in 2007 and the proportion of all aortic valve implantations performed as TAVIs increased from $<1 \%$ in 2007 to $>10 \%$ in 2012. ${ }^{19}$ Due to the time frame reported, the full influence of TAVI on surgical AVR is not apparent based on the data available in this study. A relatively consistent increase in the number of surgical AVRs performed has been observed to date, but it is unclear whether this trend will continue.

A significant and consistent increase in both mitral valve and thoracic aortic surgical activity has been observed. Activity in these adult cardiac surgery subspecialities is likely to be primarily driven by the background ageing population. However other factors such as an increase in incidental detection of thoracic aortic pathology associated with more frequent cross-sectional imaging and a move toward earlier intervention in patients with mitral valve pathology are likely to have contributed. The increase in activity across these smaller surgical subspecialties has important implications for training and service provision.

Based on the logistic EuroSCORE, ${ }^{12}$ there has been a consistent increase in the risk profile of patients undergoing cardiac surgery. This has been primarily driven by an increase in patient age but other recognized risk factors, including recent myocardial infarction and active endocarditis have also increased. Conversely, the proportion of patients with impaired ventricular function has gradually reduced over time. The proportion of patients requiring urgent surgery has increased and this corresponds with a decline in surgery performed on an elective basis.

Publication of this data provides the UK public with the confidence that NHS cardiac surgery produces satisfactory outcomes and that poorly performing hospitals or surgeons would be identified. Because the data collection is mandatory (rather than voluntary), and publication of hospital/ surgeon-specific results is in the public domain, this reassurance about the national safety of adult cardiac surgery in the United Kingdom is unique. As well as the transparency that outcome publication provides, there is a system of governance so that surgeons or hospitals with outcomes outside expected limits are notified so that action can be initiated. ${ }^{20}$ The influence of this strategy over the longer term has not previously been published. However, this policy remains controversial and among the primary concerns regarding the publication of surgical outcome data are that it may encourage risk-averse behavior. ${ }^{21,22}$

Patients requiring emergency or salvage surgery could be considered at the greatest risk of inappropriately risk-averse decision making. In addition, in the latter patient group riskadjustment models perform poorly with inadequate adjustment, ${ }^{23}$ and therefore these procedures were excluded from public reporting in the United Kingdom toward the end of the study period. Whether the improvements in outcomes 
reported during this era are merely associated with, or caused directly, by the influence of audit, comparison of outcomes at hospital and surgeon level, greater transparency or indeed public reporting itself, cannot be answered from this retrospective data.

Although there have been substantial stepwise changes in outcomes analysis and public reporting during the era of practice reported here, there is no evidence that this has directly influenced contemporary activity. Changes in patient profiles and procedures can be explained by evolving clinical demand. As seen in Figure 7, perhaps the most important achievement during this era has been the reduction in mortality despite increase in patient risk, and this trend has been relatively consistent and smooth since 2002. Although governance analyses may have contributed to improved outcomes, the drivers of this trend will inevitably be multifactorial. Improved preoperative assessment, multidisciplinary team working, intraoperative techniques and postoperative management are all likely to have played a role. The increased adoption of percutaneous treatment options may also have contributed to improved outcomes in conventional cardiac surgery.

As with any large retrospective clinical database analysis, there are limitations to this study. The dataset available for the study includes data up until March 2016, meaning more recent trends in activity and outcomes are not described. Some missing data are inevitable, but previous analyses of UK National Institute for Cardiovascular Outcomes Research data have demonstrated the rate of missing data for most key variables to be very low. ${ }^{13,19,23}$ Capturing granular clinical data in a format that is easy to subsequently analyze on a large scale is a challenge. Patients and clinical conditions are highly variable and as such it is inevitable that the reasons for certain patterns observed in the data cannot be precisely explained in a study of such a scale. As a result, only limited statistical analyses for linear trends over time have been performed. More detailed publications of data related to specific procedure groups are planned in the future.

Although other large national datasets are established and have been utilized to analyze trends, ${ }^{9,15,24-26}$ direct countryto-country comparisons are unlikely to be helpful. Many different factors contribute to the provision of cardiac surgical services on a national level. These include, but are not limited to, the resources of the country, the health care system and the underlying population, and prevalence of heart disease. The United Kingdom and Ireland are 2 economically developed countries with well-established comprehensive public health care systems and as such any comparisons would need to be put in this context. Germany has a larger population but with many commonalities to the United Kingdom and Ireland and similar trends of declining isolated CABG surgery and an increase in surgery for structural heart disease have been observed in the German Heart Surgery Report. ${ }^{9}$

\section{CONCLUSIONS}

This study, which covers all cardiac surgery procedures performed in the United Kingdom between fiscal years 2002 and 2016, demonstrates that despite an increase in patient risk profile, there has been a consistent reduction in inhospital mortality. Cardiac surgery has adapted and evolved with significant changes in case-mix and procedures performed. Although there were successive iterations in public outcome reporting between 2005 and 2016, there has been no stepwise influence on annual activity, but an association with sustained improvement in outcomes.

\section{Conflict of Interest Statement}

The authors reported no conflicts of interest.

The Journal policy requires editors and reviewers to disclose conflicts of interest and to decline handling or reviewing manuscripts for which they may have a conflict of interest. The editors and reviewers of this article have no conflicts of interest.

The authors are members of the Society for Cardiothoracic Surgery in Great Britain and Ireland (SCTS) and thank all members of the SCTS who have contributed to the SCTS Database. A more detailed account of activity and outcomes over this era can be found in the SCTS Blue book series. The authors also thank the UK National Institute for Cardiovascular Outcomes Research for its role in the UK National Adult Cardiac Surgery Audit (NACSA). In addition, the authors thank Anthony Bradley and Jiaqiu Wang for their assistance in providing NACSA data.

\section{References}

1. Cohn LH. Fifty years of open-heart surgery. Circulation. 2003;107:2168-70.

2. English TA, Bailey AR, Dark JF, Williams WG. The UK cardiac surgical register, 1977-82. BMJ Clin Res Ed. 1984;289:1205-8.

3. Keogh BE, Dussek J, Watson D, Magee P, Wheatley D. Public confidence and cardiac surgical outcome. Cardiac surgery: the fall guy in medical quality assurance. BMJ. 1998;316:1759-60.

4. Bridgewater B. Cardiac registers: the adult cardiac surgery register. Heart. 2010; 96:1441-3.

5. Grant SW, Hickey GL, Cosgriff R, Cooper G, Deanfield J, Roxburgh J, et al. Creating transparency in UK adult cardiac surgery data. Heart. 2013;99:1067-8.

6. Hannan EL, Kilburn H Jr, O’Donnell JF, Lukacik G, Shields EP. Adult open heart surgery in New York State: an analysis of risk factors and hospital mortality rates. JAMA. 1990;264:2768-74

7. Hannan EL, Cozzens K, King SB, Walford G, Shah NR. The New York State Cardiac Registries: history, contributions, limitations, and lessons for future efforts to assess and publicly report healthcare outcomes. J Am Coll Cardiol. 2012;59: 2309-16.

8. Shahian DM, Edwards FH, Jacobs JP, Prager RL, Normand S-LT, Shewan CM, et al. Public reporting of cardiac surgery performance: part 1-history, rationale, consequences. Ann Thorac Surg. 2011;92(3 Suppl):S2-11.

9. Beckmann A, Meyer R, Lewandowski J, Markewitz A, Gummert J. German heart surgery report 2019: the annual updated Registry of the German Society for Thoracic and Cardiovascular Surgery. Thorac Cardiovasc Surg. 2020;68:263-76.

10. Hickey GL, Grant SW, Cosgriff R, Dimarakis I, Pagano D, Kappetein AP, et al. Clinical registries: governance, management, analysis and applications. Eur J Cardiothorac Surg. 2013;44:605-14. 
11. Hickey GL, Cosgriff R, Grant SW, Cooper G, Deanfield J, Roxburgh J, et al. A technical review of the United Kingdom National Adult Cardiac Surgery Governance Analysis 2008-11. Eur J Cardiothorac Surg. 2013;45:225-33.

12. Roques F, Michel P, Goldstone AR, Nashef SAM. The logistic EuroSCORE. Eur Heart J. 2003;24:882-3.

13. Grant SW, Hickey GL, Dimarakis I, Trivedi U, Bryan A, Treasure T, et al. How does EuroSCORE II perform in UK cardiac surgery; an analysis of 23740 patients from the Society for Cardiothoracic Surgery in Great Britain and Ireland National database. Heart. 2012;98:1568-72.

14. Nashef SAM, Roques F, Sharples LD, Nilsson J, Smith C, Goldstone AR, et al. EuroSCORE II. Eur J Cardiothorac Surg. 2012;41:734-45.

15. Fernandez FG, Shahian DM, Kormos R, Jacobs JP, D'Agostino RS, Mayer JE Jr, et al. The Society of Thoracic Surgeons National database 2019 annual report. Ann Thorac Surg. 2019;108:1625-32.

16. Beckmann A, Funkat A-K, Lewandowski J, Frie M, Schiller W, Hekmat K, et al. Cardiac surgery in Germany during 2012: a report on behalf of the German Society for Thoracic and Cardiovascular Surgery. Thorac Cardiovasc Surg. 2014; 62:5-17.

17. Banning AP, Baumbach A, Blackman D, Curzen N, Devadathan S, Fraser D, et al. Percutaneous coronary intervention in the UK: recommendations for good practice 2015. Heart. 2015;101(Suppl 3):1-13.

18. Bhatnagar P, Wickramasinghe K, Wilkins E, Townsend N. Trends in the epidemiology of cardiovascular disease in the UK. Heart. 2016;102:1945-52.

19. Grant SW, Hickey GL, Ludman P, Moat N, Cunningham D, de Belder M, et al. Activity and outcomes for aortic valve implantations performed in England and
Wales since the introduction of transcatheter aortic valve implantation. Eur $J$ Cardiothorac Surg. 2015;49:1164-73.

20. Society for Cardiothoracic Surgery in Great Britain and Ireland website homepage. Available at: https://scts.org/outcomes/. Accessed November 7, 2020

21. Jahangiri M, Bilkhu R, Borger M, Falk V, Helleman I, Leigh B, et al. The value of surgeon-specific outcome data: results of a questionnaire. Eur J Cardiothorac Surg. 2016;50:196-200.

22. Westaby S, Baig K, Pepper J. Publishing SSMD: the risks outweigh the benefits Bull Roy Coll Surg Engl. 2015;97:155-9.

23. Grant SW, Hickey GL, Dimarakis I, Cooper G, Jenkins DP, Uppal R, et al. Performance of the EuroSCORE models in emergency cardiac surgery. Circ Cardiovasc Qual Outcome. 2013;6:178-85.

24. Siregar S, de Heer F, Groenwold RH, Versteegh MI, Bekkers JA, Brinkman ES, et al. Trends and outcomes of valve surgery: 16-year results of Netherlands Cardiac Surgery National database. Eur J Cardiothorac Surg. 2014;46:386-97.

25. Vikholm P, Ivert T, Nilsson J, Holmgren A, Freter W, Ternström L, et al. Validity of the Swedish Cardiac Surgery Registry. Interact Cardiovasc Thorac Surg. 2018;27:67-74.

26. Rao C, Zhang H, Gao H, Zhao Y, Yuan X, Hua K, et al. The Chinese Cardiac Surgery Registry: design and data audit. Ann Thorac Surg. 2016;101:1514-20.

Key Words: cardiac surgery, patient outcomes, activity trends, mortality, EuroSCORE, coronary artery bypass graft, mitral valve, aortic valve 